\title{
O SURGIMENTO DOS DOCUMENTOS PESSOAIS E OS MODERNOS PROCESSOS DE IDENTIFICAÇÃO: O CASO DO HAITI'
}

\author{
THE ADVENT OF DOCUMENTS AND MODERN IDENTIFICATION \\ PROCESSES: THE CASE OF HAITI
}

DOI: 10.5380/cg.v10i2.77430

\author{
Nathanael Pericles ${ }^{2}$
}

Arlene Martinez Ricoldi3

\begin{abstract}
Resumo
O artigo irá tratar das raízes do problema histórico da "falta de documentação" no Haiti e seu contexto atual. Com base em uma pesquisa bibliográfica e documental, o trabalho irá abordar o surgimento dos documentos como técnicas de controle da população, a partir do surgimento do que Foucault (2005) denomina biopoder. Originários do continente europeu, os documentos de identidade se disseminam por todo o mundo para permitir, entre outras razões (como reconhecimento e garantia de direitos sociais), o deslocamento humano. O centralizado sistema haitiano de documentação, em meio aos problemas socioeconômicos e políticos do país, sofre com a falta de recursos, inconsistências e ausência de qualificação de pessoal burocrático, sem um impacto consistente no sentido de democratizar seu acesso. Ainda assim, os avanços conquistados parecem resultar em grande parte na forte onda migratória que o país tem observado desde o início dos anos 2010.
\end{abstract}

Palavras-Chave: Documentos pessoais; Estado; Haiti; Cidadania; Burocracia; Políticas públicas.

\begin{abstract}
This article will address the roots of the historical problem of undocumentation in Haiti and its current context. Based on a bibliographic and documentary research, the paper will address the emergence of documents as techniques for population control, from the emergence of what Foucault calls biopower. Originating in the European continent, the documents of identification, spread throughout the world, to allow, among other reasons (such as recognition and guarantee of social rights), human displacement. The centralized Haitian documentation system, in the midst of the country's socio-economic and political problems, suffers from a lack of resources, inconsistencies and a lack of qualification of bureaucratic personnel, without a consistent impact on the path to democratize their access. Even so, the advances achieved seem to result largely from the strong migratory wave that the country has known since the beginning of the $2010 \mathrm{~s}$.
\end{abstract}

Keywords: Personal documents; State; Haiti; Citizenship; Bureaucracy; Public policy.

\footnotetext{
${ }^{1}$ Este artigo está licenciado sob a Licença Creative Commons Attribution (CC BY 4.0), sendo permitido o compartilhamento com reconhecimento da autoria e publicação inicial nesta revista.

2 Doutorando em Ciências Humanas e Sociais na Universidade Federal do ABC. E-mail: nathanael.pericles@gmail.com.

3 Doutora em sociologia pela Universidade de São Paulo e professora adjunta da Universidade Federal do ABC.

E-mail: arlenericoldi@gmail.com.
} 


\section{INTRODUÇÃO}

Os documentos civis tornaram-se indispensáveis para comprovar a identidade cívica das pessoas. No mundo moderno, a palavra não basta para comprovar que somos quem dizemos ser. Além disso, os documentos também viabilizam acesso a direitos básicos como educação, direitos relativos ao trabalho, ao voto, registros de propriedade, bem como levar uma vida ativa e participativa na sociedade, em seus aspectos sociais, políticos e econômicos.

O interesse nos documentos de identidade, que motivou a elaboração deste artigo, teve início no contexto de uma pesquisa que realizamos na formação em nível de maîtrise (equivalente ao mestrado) em Antropologia (PERICLES, 2016)4 ${ }^{4}$,sobre a escolha de prenomes por parte dos pais e mães no Haiti. Vimos que os problemas da certidão de nascimento constituem um obstáculo ao respeito da escolha simbólica dos pais: alguns oficiais optam por escrever os primeiros nomes de qualquer maneira. Às vezes, mudam os primeiros nomes escolhidos pelos pais. A pesquisa coincidiu com a promulgação do julgamento TC / 0168/1355, pelo Tribunal Constitucional da República Dominicana, para privar todos os cidadãos dominicanos de origem haitiana, nascidos após 1927, da sua cidadania. De fato, além dos problemas raciais expressos por essa decisão, adotada em 23 de setembro de 2013, descobriu-se que há centenas de haitianos e haitianas sem documentos de identidade. A lei haitiana penaliza a circulação sem documentos de identidade no país. A identificação de todos os adultos em território haitiano é obrigatória desde o decreto de $1^{\circ}$ de junho de $2005^{6}$ (MONITEUR, 2005). No Brasil, embora não exista lei que obrigue o cidadão a portar seus documentos, curiosamente todos acreditam que eles são obrigatórios (DAMATTA, 2002).

A pesquisa buscou investigar o sistema de identificação do Haiti para compreender porque o Estado não consegue fornecer a certidão de nascimento para a maioria de seus cidadãos, visto que esse é um registro básico para obtenção dos outros documentos. Para isso, foi fundamental compreender a importância dos registros de identidade e entender a história dos documentos, as circunstâncias de sua criação e implicações sociais e políticas. "Qual é o seu significado no contexto dos Estados-nacionais modernos que surgiram pregando a igualdade e a liberdade individual e, no entanto, institucionalizaram essa pletora de papéis que, de fato, controlam rigidamente as nossas existências como cidadãos livres?" (DAMATTA, 2002, p. 44).

\footnotetext{
$4 \mathrm{O}$ trabalho final que foi concluído, mas não foi defendido, tratou de um estudo de caso de uma comunidade de Thomazeau, comuna haitiana localizada no departamento Oeste no Arrondissement de Croix-desBouquets, a 34 quilômetros da cidade de Port-au-Prince.

5 A decisão do Tribunal Constitucional não apenas negou o recurso de Juliana Deguis, que pleiteava a emissão de uma cédula de identidade e eleitoral, mas também estendeu seus efeitos às centenas de milhares de pessoas que compartilham de sua situação, embora não tenham participado do processo (PERDOMO CORDERO, 2016).

${ }^{6}$ Artigo 27: "A partir de 1 de janeiro de 2008, qualquer pessoa de idade avançada, surpreendida sem o seu Bilhete de Identidade Nacional, pagará uma multa de quinhentos (500) Gourdes em minutos redigidos por um policial, pronunciado imediatamente e todos os negócios cessando pelo tribunal de paz”.
} 
O presente artigo faz, portanto, uma exploração da história dos documentos de identidade no Haiti, desde o período colonial até os dias de hoje, mostrando a importância dos documentos para a questão da identidade, da construção da pessoa e do cidadão. De que maneira os documentos de identidade estão ligados à questão da cidadania, já que o Estado é o depositário dos aparelhos administrativos que fornecem documentos, e quais as medidas tomadas a partir das leis, acesso aos documentos e categorias criadas? Qual é o seu significado na sociedade haitiana?

Para melhor compreender o problema formulado, é preciso conhecer o contexto que leva o Estado a querer controlar melhor a identidade. Não se trata de uma antropologia dos códigos, mas de compreender as práticas, compreender como a identificação influi na construção das categorias de pessoas. A questão será colocada em oposição ao Estado, que é, reconhecemos, um “identificador poderoso, não porque ele seria capaz de criar 'identidades' no sentido forte do termo - em geral, ele é incapaz -, mas porque ele tem os recursos materiais e simbólicos para produzi-las [...]"(BRUBAKER, 2001, p. 76).

O problema da indocumentação, presente em vários países do mundo, vem sendo tratado no campo dos direitos. É alvo de preocupação de organizações internacionais, como a ONU (1985), tanto para fins de comprovação da cidadania e pertencimento à determinada sociedade nacional e o gozo dos direitos coextensivos quanto no sentido de promover o registro dos fatos da vida civil (nascimento, casamento e morte), que auxiliariam o planejamento público. No Brasil, o problema da indocumentação ainda é pouquíssimo estudado (RICOLDI, 2017), tanto no sentido de sua extensão real (quantas pessoas são indocumentadas) quanto no significado emprestado aos documentos. A relação com a normatização burocrático legal para dar acesso a direitos, especialmente para aquelas com um maior distanciamento desses códigos (CORDEIRO, 2007), ou mesmo, como faremos aqui, como instrumento de controle e regulação do Estado Moderno.

Nesta investigação, utilizamos uma pesquisa bibliográfica exploratória que visou esclarecer um problema social que está mais ou menos definido: o Estado haitiano falha em fornecer documentos aos seus cidadãos (BERTIN, DROGUE, 2012). Esse problema torna-se ainda mais grave tendo em vista se tratar de uma população que constantemente se desloca, em razão das dificuldades sociais, econômicas e políticas enfrentadas pelo país por décadas7 . O problema da identificação no Haiti, devidamente documentado por organizações como o GARR (Grupo de Apoio para Repatriados e Refugiados) e o SJRM-Haiti (Serviço Jesuíta para Migrantes e Refugiados no Haiti), porém, não é usualmente abordado por sociólogos ou antropólogos.

O texto está organizado em quatro partes: após a introdução, será apresentada uma breve história da criação de documentos de identidade, o papel da Igreja e do Estado e a organização do

\footnotetext{
7 Pode-se considerar que a história do Haiti, desde sua independência, é atravessada por instabilidades políticas, golpes de Estado e problemas econômicos, como grande parte das ex-colônias do continente americano, com o agravante, porém, de intervenções constantes da comunidade internacional, especialmente os EUA a partir do século XX, contando, inclusive, com ocupação efetiva estadunidense em seu território. Para um panorama sobre a história do Haiti, cf. Metz (2001).
} 
registro civil nas Américas, em especial no Haiti; a segunda parte se concentra nos modernos serviços de registro civil, a emissão de seu principal documento, a certidão de nascimento, e os desdobramentos problemáticos desse desenvolvimento no Haiti; na terceira parte, as várias medidas dos governos haitianos para estender o atraso do registro tardio das certidões de nascimento. A conclusão trata sobre o avanço do registro de certidões de nascimento devido, em grande parte, à onda migratória que o país observa nos últimos nove anos (a migração de haitianos para o Brasil e para o Chile).

\section{OS DOCUMENTOS DE IDENTIDADE ATRAVÉS DA HISTÓRIA}

Segundo Foucault, é a partir do século XVIII que se pode observar o surgimento de uma biopolítica, cujo objeto será o corpo vivente, suporte dos processos biológicos, tais como nascimento, mortalidade, saúde e duração da vida, que serão objeto de uma nova ciência, a demografia. A noção de "biopolítica" é usada para designar a evolução histórica do processo civilizatório, as tecnologias utilizadas pelo Estado para fins de controle social, tanto no nível dos indivíduos como das populações. Por assim dizer, das tecnologias de subjetivação implantadas pelas autoridades políticas em sua busca pelo domínio e controle sobre outros agentes sociais. “A vida agora se tornou um objeto de poder. Antigamente, só havia assuntos jurídicos dos quais se podia tirar propriedades, e também a vida. Agora existem corpos e populações " ( FOUCAULT, 1994, p. 194). O registro civil e, posteriormente, os documentos de identidade, constituem instrumentos de consumação desse biopoder.

Foucault (2005) afirma que os documentos de identidade são uma tecnologia de visibilidade que permite ao Estado controlar e regular a população. A gênese dessa identificação escrita é feita, em grande parte, em conexão com o controle da mobilidade das pessoas. Em particular, certos grupos, por serem móveis, estão sujeitos a controles e medidas especiais de identificação, como criminosos e prisioneiros em fuga, grupos de viajantes, principalmente em tempos de epidemias, que saem de áreas contaminadas e são submetidos a controles escritos.

Objetivamente, essas técnicas de identificação têm origem em uma série de processos colocados em marcha, que unem tanto práticas científicas da época como as técnicas de antropologia criminal lombrosianas. Usando a medição do corpo, que derivou nas técnicas de reconhecimento de criminosos reincidentes, como aquelas desenvolvidas pelo policial francês Alphonse Bertillon (algumas abandonadas, outras ainda utilizadas, como o retrato falado, técnicas grafológicas e fotografias de frente e de perfil); e, por fim, o desenvolvimento da demografia (GALEANO, 2012).

O uso dos documentos escritos, produzidos pela burocracia para comprovar nossa identidade, nos parece, hoje, normal (DENIS, 2000), mas, como vimos, é uma invenção tardia na história humana. Ao longo da história, testemunhamos a elaboração de várias técnicas de 
identificação, que implicam em um trabalho permanente. Não é fácil definir a identidade, visto que essa noção é contraditória e cambiante (MACDONALD, 1978). A construção dos conhecimentos administrativos relacionados à identidade das pessoas permite sintetizar os resultados em uma proposição: não há identidade, existem apenas processos de identificação (BRUBAKER, 2001).

Durante séculos, o corpo vai sendo apreendido pouco a pouco por técnicas de identificação, de maneira cada vez mais confiável nos documentos administrativos. A expansão que conheceu a escrita renovou o esforço de registrar e inventariar os bens e as pessoas. "As informações fornecidas se tornam, todavia, essenciais para compreender a criação da identificação, porque vemos a identidade, o nome e o estatuto social e profissional que, pela perspectiva do registro, se formaliza" (DE LARIVIÈRE, 2007).

Os primeiros registros feitos ao longo da história não têm o objetivo de recensear a população, mas avaliar sua fortuna e estabelecer o montante coletável. Ainda que esses registros de identidade sejam baseados em uma questão financeira ligada ao status social, todavia desempenham um papel importante nos processos de identificação. As informações fornecidas são, entretanto, essenciais para a compreensão da gênese da identificação, pois "mostra a identidade, o nome e o status social e profissional que, por meio do registro, é formalizado" (DE LARIVIERE, 2007).

A partir do século XIII, a Igreja e o poder público desempenharam um papel cada vez maior no registro e depois na identificação dos indivíduos. Entre os séculos XIII e XV, houve um aumento de documentos emitidos por governos urbanos e instituições monárquicas que buscavam identificar pessoas. Ao longo dos anos, o trabalho administrativo dos Estados tornou-se mais preciso e mais elaborado. Com sistemas burocráticos renovados, as pessoas são registradas a partir de vários critérios. Habilidades sociais complexas são adicionadas ao nome; para a classe dominante, é o status privilegiado que é levado em conta, mas, para a maioria, a atividade profissional é o componente essencial da identidade (DE LARIVIÈRE, 2007). Embora esses registros de identidade sejam baseados na posição econômica em relação à posição social, eles desempenharam um papel importante nos processos de identificação. Nesse período, também devemos considerar os certificados individuais que informam a identidade daqueles que os usam (DE LARIVIÈRE, 2007).

Esses documentos permitiam que os indivíduos se movessem livremente de um lugar para outro. Eram “condutas seguras”, uma espécie de privilégio. No final da Idade Média, eles serão substituídos pelo termo "passaporte", que se torna um documento obrigatório para atravessar fronteiras. Houve o desenvolvimento de várias técnicas de identificação no espaço de algumas décadas. Na França, os primeiros registros civis apareceram no século XVI, tornando obrigatória a manutenção de registros de batismos pelos párocos e seu depósito no tribunal civil em questão. Por decreto, em 1792, a Assembleia Nacional secularizou o registro civil e o confiaram aos prefeitos (NOIRIEL, 1993).

A questão dos documentos de identidade, desde o advento do Estado-nação, está relacionada à instituição estatal, que identifica uma população sobre um território. Esses documentos dão acesso 
a uma cidadania com direitos civis, políticos e sociais. A palavra "cidadania" é um ideal desenvolvido no Ocidente e talvez inatingível em sua completude. "Isto quer dizer que a cidadania inclui várias dimensões e que algumas podem estar presentes sem as outras" (CARVALHO, 2016). Cada indivíduo passa a se considerar cidadão ou cidadã a partir da emissão de uma identidade diante do "aparelho central" (CARRARA, 1990). Assim, a cidadania faz parte da lealdade a um Estado e a identificação com uma nação. Como afirma Carvalho (2016), as duas nem sempre aparecem juntas, a identificação com a nação pode ser mais forte e vice-versa. "Em geral, identidade nacional se deve a fatores como religião, língua e, sobretudo, lutas e guerras contra inimigos comuns” (CARVALHO, 2016, p. 18).

No caso haitiano, já na sua primeira Constituição (1805) estabeleceram-se suas bases jurídicas, que permitiram a cada Conselho um registro civil para os haitianos/as. No entanto sempre houve uma lacuna entre o Estado e a população haitiana, especialmente nas áreas rurais (CASIMIR, 2006). Essa lacuna se tornará então conhecida, uma divisão entre sua população: aquela que conforma as massas camponesas (o "país para fora”) (BARTHÉLÉMY, 1993) e as elites.

Essas pessoas do "país para fora" ficarão longe da vida organizada nas grandes cidades e viverão à sua maneira, mesmo que isso signifique viver sem uma certidão de nascimento e sem educação formal. Os camponeses haitianos não parecem ter canais oficiais de expressão (LAENNEC, 2009). Autores explicam a recusa da população em se vincular ao Estado, evitando até mesmo registrar-se (BERTIN, DROGUE, 2012). A explicação disso, segundo Moral (1961), relaciona-se com a recusa da população quanto ao Estado e à falta de reconhecimento desse segmento por este.

Qual é então o papel do Estado em manter essa ordem? Por que a população não é incentivada a se cadastrar? Como diz Moral (1961), isso é um desafio, especialmente por parte dos camponeses. Está claro que o sistema de registro civil haitiano não cumpre essas funções de registrar todos os seus cidadãos. Como Coordenadora do Grupo de Apoio a Refugiados e Repatriados, Lespinasse argumenta:

O sistema haitiano nunca conseguiu registrar e identificar adequadamente todos os haitianos. Nunca conseguiu cadastrar todos os filhos que nascem a cada ano no país, nem fornecer, sem dificuldade, uma cópia do ato a quem necessitar. Boa parte da população haitiana, portanto, evolui, ao longo de sua existência, sem ser registrada e sem possuir documento de identidade. (GARR, 2008).

Segundo nossa pesquisa anterior (PÉRICLES, 2016), os cidadãos haitianos entendem a necessidade de se cadastrar nos cartórios de registro civil, pois, para matricular os filhos em uma escola, é obrigatória a certidão de nascimento. A educação é levada muito a sério, já que representa uma marca de distinção, conforme afirma Bourdieu (1979), e é considerada a melhor saída da pobreza (MENARD, 2013). Em todo o país, mais de 350 mil crianças e adolescentes permanecem excluídas da escola primária ou secundária (HUMAN RIGHTS WATCH, 2018). 


\section{O REGISTRO CIVIL E A CERTIDÃo DE NASCIMENTO - PROBLEMA CONTEMPORÂNEO PARA O HAITI}

No caso do Haiti, de forma similar ao que ocorre no Brasil, o registro que dá acesso aos outros documentos é a certidão de nascimento. É um documento de validade jurídica sob o olhar do Estado e, sem ele, o indivíduo pode sofrer várias restrições nas sociedades mencionadas. Para organizar os registros de nascimento, leis foram adotadas para legitimar, regulamentar, manter e melhorar de maneira permanente o processo de registro (ONU,1985). A edificação do sistema de registro civil se dá por meio de medidas legislativas que definem o tipo de fato civil que devem declarar.

A organização do registro civil difere dependendo do país. Esses serviços podem ser organizados, de forma geral, de duas maneiras: descentralizados ou centralizados (ONU,1985). O sistema descentralizado é caracterizado por uma administração de escritórios locais de registro pelas autoridades regionais. Não há um escritório nacional para supervisionar o sistema local, exceto talvez por um órgão responsável por coordenar o estabelecimento de estatísticas vitais. O Brasil pode ser considerado um exemplo de descentralização, com cada cartório responsável pela validação dos documentos emitidos, bem como pela guarda dos registros.

No Haiti, existe um sistema centralizado, composto pelo Ministério da Justiça e pelos Arquivos que cuidam do registro civil. Isso significa que os registros são feitos localmente, no entanto somente são válidos quando enviado ao arquivo central que controla dos registros.

Existe um cartório em cada comuna para servir as seções comunais ${ }^{8}$. O problema da distância dos escritórios de registro civil da população é frequentemente levantado como um elemento constitutivo do número de não declarações de nascimentos. "A distância entre o agricultor e o escritório do estado civil é tão grande que ele fica desanimado e desinteressado em declarar o nascimento de seus filhos, daí o problema da taxa de nascimentos não registrada no país” (ST SAUVEUR, 2010, p.13).

Bertin e Drogue (2012) explicam que, para economizar recursos, cópias de formulários em branco são feitas, enquanto cada um deveria ter um número específico. Isso pode levar a diversas certidões de nascimento com o mesmo número. O relatório de Saint Michel de l'Attalaye de 24 de abril de 1990 afirma que "somente para o ano de 1989, o oficial Félix Pierre entregou 1500 certidões de nascimento com o $\mathrm{n}^{\circ} 76270 \mathrm{D}$, mais de 500 com o $\mathrm{n}^{\circ} 63050$ I (...)”. Muitas certidões de nascimento em circulação contêm erros de forma, ou erros na grafia dos nomes e sobrenomes dos pais ou da criança (GARR, 2013). Por outro lado, muitos registros civis parecem nunca terem sido

\footnotetext{
8 Para efeito de compreensão, é necessário explicar brevemente como se organiza administrativamente o Haiti. Seu território de $27.065,30 \mathrm{~km}^{2}$ está geograficamente dividido em 10 departamentos (départements), cujas subdivisões se dão, sucessivamente, em 42 vilas (arrondissements), 140 comunas (communes), 64 bairros (quartiers) e 570 seções comunais (sectionscommunales). Essas últimas constituem a menor divisão administrativa do Haiti (Constituição 1987, art.62). (CommissionNationale a la Reforme Administrative/CNRA,2002).
} 
enviados ao Ministério da Justiça para serem arquivados ${ }^{9}$. Essa violação das regras complica o arquivamento de registros e, ao mesmo tempo, impede que muitas pessoas recuperem seus dados. O diretor do Arquivo Nacional, Jean Wilfrid Bertrand, declara que mais de um milhão de haitianos evoluem durante toda a sua existência sem estarem registrados. (LOUIS, 2020)

Confrontados com a complexidade de certos procedimentos, os cidadãos encontram-se desamparados e são vítimas de certos criminosos que fingem ser facilitadores dos serviços do Estado. Outros recorrem a um advogado; porém o ônus financeiro de tal solução é um fardo pesado demais para a maioria dos orçamentos haitianos (BERTIN, DROGUE, 2012).

Em 2008, de acordo com um estudo do Programa das Nações Unidas para o Desenvolvimento (PNUD) sobre o registro civil, no Haiti quase 50\% dos bairros não têm escritórios de registro civil e 81,1\% desses escritórios estão em áreas urbanas. São 189 escritórios de registro civil para todo o território haitiano (CHALLENGES,2016). Apenas 5\% das seções comunais (de um total de 570), têm um escritório para registrar nascimentos, região que concentra 60\% da população do país. O número de escritórios de registro civil é considerado insuficiente para atender o número de habitantes da população.

\section{MEDIDAS TOMADAS PELOS DIFERENTES GOVERNOS PARA ALIVIAR O PROBLEMA}

À medida que o uso de documentos de identidade cresce, é também crescente sua codificação e institucionalização. Há um aumento contínuo de requisitos de identificação novos, mais precisos, escritos e com novas categorias descritivas. Ao longo do tempo, técnicas novas são desenvolvidas, como: coleta de impressões digitais, medições antropométricas, tentativa de estabelecer padrões físicos, DNA humano, identificação visual etc. O aprimoramento das técnicas vem se traduzindo também em uma série de tecnologias de biovigilância e controle, como o uso de leitores biométricos, já extremamente difundidos e popularizados.

A complexidade e especialização crescentes da cultura moderna exigem para o seu aparelho exterior um funcionário pessoalmente desinteressado e rigorosamente objetivo, tendo em vista que o uso da identificação escrita é estimulado pelo desenvolvimento da assistência e da questão social. Apesar do constante e, de certo modo, rápido incremento das tecnologias de identificação, a história dos papéis de identidade também é de incerteza e fraude. Os documentos também se tornaram trocáveis, revendidos, falsificados. As autoridades não buscariam apenas verificar a identidade, mas os sinais de autenticidade de seus próprios papéis (DENIS, 2006).

O problema da indocumentação no Haiti é reconhecidamente grave, bem como os problemas de falsificação dos actes de naissance, equivalentes às certidões de nascimento. Essas últimas são

9 O órgão responsável por esse serviço é o Arquivo Nacional do Haiti (ArchivesNationales d'Haïti/ ANH). 
documentos facilmente falsificáveis, e, por essa razão, não são consideradas um documento confiável pelas autoridades haitianas, não se permitindo a sua utilização em procedimentos cotidianos, como abrir uma conta bancária, comprar terras ou obter um passaporte. O documento que tem real força probatória é o chamado "extrato dos arquivos"10, que, desde fevereiro de 2008, é emitido com um holograma para dificultar a falsificação, embora não a impeça totalmente (BERTIN; DROGUE, 2012).

Segundo Celicourt (2017, p. 5-6), o desinteresse das autoridades políticas é patente, dado que a lei de registro civil tem 40 anos, formulada ainda no período da ditadura de Jean Claude Duvalier ${ }^{11}$, e as medidas tomadas no sentido de melhorar esse serviço vem sendo efetivadas na forma de decretos $^{12}$, bem como a diminuta dotação orçamentária disponibilizada para a questão.

Ainda assim, os problemas espinhosos e variados colocados pela organização do registro civil provocaram interesse, especialmente por causa da emigração maciça (Ministère de la Justice, 1984). Essas dificuldades estão ligadas à incompetência técnica e desconhecimento da legislação atinente por parte dos funcionários responsáveis ${ }^{13}$, causando falhas e irregularidades no registro civil.

Após a queda de Duvalier-filho, em fevereiro de 1986, a Junta Militar, que governou de abril de 1987 a fevereiro de1988, liderada por Henri Namphy, decretou um período legal de 25 meses para permitir o registro tardio de um nascimento. Porém parece que o decreto foi saudado com indiferença: exceto por algumas raras iniciativas de algum comissário do governo ou registrador civil, o sistema judicial se pôs à inércia.

A próxima medida de relevo para enfrentar os problemas do registro civil foi tomada pelo governo eleito nas primeiras eleições do país após a ditadura, em 1990, que elegeu o padre católico Jean-Bertrand Aristide. Aristide, associado à Teologia da Libertação (no Haiti, o denominado movimento se chama ti-egliz, ou "pequeninos da Igreja"), havia combatido o regime Duvalerista ${ }^{14}$. No final de seu mandato, mais uma medida por meio de decreto, promulgado em 1995, concedeu a qualquer pessoa privada de certidão de nascimento um período de cinco anos para regularizar sua situação. Para além do registro tardio, uma das medidas, não menos significativa, foi também

\footnotetext{
${ }^{10}$ Devido aos diversos problemas relatados, a única forma de comprovar a autenticidade de um documento no Haiti é solicitar um "extrato" desses documentos retirado dos Arquivos Nacionais do Haiti, no qual são armazenados os registros civis.

${ }_{11}^{11}$ Jean Claude Duvalier foi ditador do Haiti de 1971-1986, conhecido por Baby Doc, assim conhecido por ser filho de François Duvalier, o Papa Doc, a quem sucede após sua morte, ascendendo ao poder com apenas 19 anos.

${ }^{12}$ Ainda que possa haver diferenças entre o Direito brasileiro e o haitiano, ambos pertencem a uma mesma linhagem do direito, chamada Civil Law (FRIEDE, 2019). O decreto diferencia-se da Lei por não passar pela aprovação na casa legislativa, e caracteriza-se por ser uma regulamentação da lei, porém sem a mesma força normativa.

${ }_{13} \mathrm{O}$ oficial de registro civil possui, segundo os textos, o status de funcionário público, podendo se cercar de funcionários para ajudá-lo. No entanto não recebe formação prévia porque não existe uma escola nem um concurso de recrutamento, já que a nomeação do oficial é frequentemente uma escolha política, feita pelo Presidente da República por recomendação do Ministro da Justiça (GARR, 2008).

14 Aristide teve um primeiro mandato conturbado, interrompido por um golpe de Estado alguns meses após sua posse, e depois retomado em outubro de 1995, após quatro anos de exílio, com o acordo de cumprir apenas o tempo restante de seu mandato interrompido (METZ, 2001).
} 
eliminar a "dupla legislação", baseada nessa cidadania de dois pesos e duas medidas para os haitianos na cidade e os camponeses ${ }^{15}$.

Em 2001, Aristide foi eleito presidente pela segunda vez e, durante seu mandato, um novo decreto foi promulgado, em 2002, com os mesmos objetivos: regularizar a emissão de certidão de nascimento das pessoas físicas. Quase dez anos depois, o mesmo problema ressurgiu em um momento no qual a questão estava no centro das notícias. Em particular, a dos haitianos na República Dominicana que se encontravam em situação ilegal e, em sua maioria, não possuíam documentos de identidade; e a dos dominicanos que se tornaram apátridas após a decisão do Tribunal Constitucional Nacional retirar a nacionalidade dos filhos de ancestrais haitianos nascidos em território dominicano ao longo de várias gerações ${ }^{16}$, condição inicialmente concedida pela Lei do Solo ${ }^{17}$.

A história do Haiti e da República Dominicana é conturbada. Os dois países, que dividem um território insular, tentam atribuir a cada uma de suas identidades nacionais uma unidade, ainda que com uma característica dual e simétrica: "um lado, o noirisme ${ }^{18}$, por outro a vontade de se identificar, num país composto por $70 \%$ de mulatres $^{19}$, a um povo de fisionomia à dominância espanhola" (CORTEN, 2011, p.43). Segundo Corten (2011), o antidominicanismo e o anti-haitianismo recíproco dos países deflagrou esse processo. A Ocupação dos EUA (1915-1934) foi um dos disparadores da migração de haitianos para a República Dominicana, com o objetivo de trabalhar no setor açucareiro, o que exigiu muita mão-de-obra barata (CASTOR, 1971). Hoje, haitianos e haitianas são encontrados nos setores agrícola (café, cacau, arroz), construção civil e até no turismo dominicano (CORTEN, 2011).

No entanto a migração de haitianos sempre foi controversa e vista como uma ameaça pelos dominicanos $^{20}$. O Programa de Identificação de Imigrantes Haitianos (PIDIH) foi criado para

\footnotetext{
15 A separação das certidões de nascimento entre "habitantes da cidade" e "camponeses" constituiu uma discriminação no Haiti. Na prática, refere-se a um grupo de cidadãos analfabetos e pobres, os camponeses, e os habitantes da cidade, aqueles que seriam "iluminados" na linguagem cotidiana (DIAL [Diffusion de l'Informationsurl'Amérique Latine], 1990, p. 2)

${ }_{16}$ Os/as haitianos(as) nascidos(as) desde 1929 na República Dominicana com pais ou avós imigrantes tornamse de fato apátridas.

${ }^{17}$ A "Lei do solo" (em latim, jus soli) e o "direito do sangue" (em latim, jus sanguinis) são noções que datam do século XIX. Significa o estado de direito atribuindo uma nacionalidade a uma pessoa em razão de seu nascimento em um determinado território. No continente americano, em países como Estados Unidos, Canadá, Chile, México, Argentina, Brasil e Equador, o direito à terra é sistematicamente obtido (BRUSCHI, 1995).

18 Noirisme, do francês noir (preto), foi um movimento haitiano que contestava o poder nas mãos de uma minoria mulattresobre a maioria negra. Para uma explicação sobre as divisões raciais no Haiti, cf. (LABELLE Michelle. Ideologie de couleur et classes sociales en Haiti. 1987. CIDIHCA).

${ }_{19}$ No sentido do sistema racial/de classes haitiano (LABELLE, 1987), no qual mulattre designa a elite mestiça (e geralmente, mais rica) do país. Nesse caso específico, refere-se à característica mestiça da população dominicana.

${ }^{20}$ Em 1984, Balaguer, ex-presidente da República Dominicana, disse: "Os haitianos, portanto, ameaçam nossa existência como um povo com uma fisionomia predominantemente espanhola" (CORTEN, 2011), afirmando, a seguir, que o papel do Estado é exterminar aqueles que cavalgaram na fronteira dominicana. A morte de pelo menos 12 mil haitianos em 1937 é um exemplo trágico. Isso explica o clima que evoluiu e continua a evoluir entre os migrantes haitianos na República Dominicana.
} 
enfrentar o problema, possibilitando obter, com a quantia de 2, 5 mil pesos (moeda da República Dominicana), um único envelope contendo um Cartão de Identificação Nacional (CIN), passaporte e extrato dos arquivos existentes, valor posteriormente reduzido para mil pesos (equivalente a cerca de US\$22).

Essa iniciativa foi lançada em julho de 2014 pelo Ministério dos Haitianos que Vivem no Exterior (MinistèredesHaitiensVivant a l'Étranger/MHAVE), em colaboração com o Arquivo Nacional do Haiti (ANH), o Escritório Nacional de Identificação (ONI) e a Direção de Imigração e Emigração (DIE) em Santo Domingo.

Esse programa foi criado após o Plano Nacional de Regularização de Estrangeiros (PNRE), posto em prática na República Dominicana. Entretanto, segundo funcionários do Estado do Haiti, esse programa já estava planejado bem antes de seu lançamento em 2014. A previsão era de abertura de quatro sites para atender à demanda, mas apenas um foi criado, que não tinha capacidade suficiente para receber todas as solicitações de documentos.

O programa planejou identificar e documentar, em dez meses, mais de 300 mil haitianos vivendo ilegalmente em território dominicano. No entanto apenas 52 mil estão inscritos no PIDIH, dos quais 2 mil receberam seus passaportes, 15 mil possuem carteira nacional de identidade e 20 mil têm certidão de nascimento. Diante desse cenário, o programa foi avaliado como um fracasso por Daniel Supplice, ex-embaixador (fevereiro de 2015 a julho de 2015) e Conselheiro Político do Presidente Haitiano Michel Martelly.

De acordo com funcionários do GARR, o fracasso do PIDIH está ligado a vários fatores. Primeiro, as pessoas não foram suficientemente informadas sobre o serviço. Em segundo lugar, também não havia instruções claras e disponíveis sobre o processo e os passos a seguir. Terceiro, dispositivos não foram colocados em prática para permitir que pessoas "sem documentos" acessem os sites sem o risco de serem deportadas, ao se identificarem por meio do cadastro (RELIEFWEB, 2015).

Supplice lamenta "que não tenhamos conseguido dar a nossos concidadãos uma certidão de nascimento provando que eles existem [...]”. A identificação dos haitianos ainda está comprometida. Ele admite a responsabilidade do Estado: "Somos responsáveis pelo que está acontecendo hoje com nossos compatriotas", e ele lembra que "se não conseguirmos identificar nossos cidadãos em casa, não vejo como faríamos isso em outro lugar (...). Já encomendei o fechamento do programa, que custou dois milhões de dólares até agora” (HAITI LIBRE, 2015).

Apesar das dificuldades, esforços no sentido de modernizar o registro civil no país têm sido empreendidos, com a implantação de serviços de emissão da Carte d'Identification (carteira de identidade), denominado Office Nationale d'Identification (ONI), que somava 147 unidades em 2017. Porém esse serviço foi liberado somente para os cidadãos adultos, e o maior problema de registro civil ainda são os actes de naissance: os serviços de saúde falham em fornecer documentos 
de bebês nascidos nesses estabelecimentos; por outro lado, cerca de $75 \%$ das mulheres no Haiti dão à luz no domicílio.

Muitas vezes, no caso do Haiti, o ato de falsificação não se trata de burlar a identificação oficial, como no caso de ocultar crimes cometidos ou outros fatos da vida civil, mas possibilitar um meio de identificação para permitir o deslocamento e demais direitos, devido às falhas do Estado haitiano em fornecer adequadamente esse serviço.

\section{CONSIDERAÇÕES FINAIS}

Formas de registro e controle da população são encontradas desde o século XIII na Europa, porém, com o surgimento do Estado-nação moderno e da burocracia, novas técnicas de identificação corporais foram sendo elaboradas e se tornando mais sofisticadas. Os documentos de identificação se tornaram o instrumento para obtenção e usufruto da condição da cidadania nacional.

Atualmente, embora de diferentes formas, os Estados modernos instituíram meios de identificar e documentar seus cidadãos. O registro de nascimento voluntário pode ser um indicador de integração no sistema legal ou social, ou ainda, da medida do exercício da cidadania em um determinado país, o que significa ser titular de direitos. Por outro lado, se há um descumprimento sistemático das regras legais, grupos marginais podem surgir e protagonizar tensões e crises permanentes. Essa marginalidade pode ser voluntária, se depender apenas da posição de indivíduos ou grupos; ou induzida, incrementando-se na medida em que as deficiências no funcionamento do sistema de registro ou dificuldades legais dificultam o acesso da documentação aos cidadãos.

Nos últimos anos, especialmente após o terremoto de 2010, o país experimentou um aumento significativo da migração para novos destinos. A partir desse mesmo ano, o Brasil recebeu 85 mil haitianos. Essa migração deu um sopro de ar fresco ao processo de registro. Desde então, esses solicitantes devem ter seu extrato de arquivos para retirar seu passaporte, embora isso não tenha ocorrido sem problemas, porque o sistema não conseguiu atender à demanda. Em 2015, a meta foi definida para aumentar a capacidade de produção de passaporte em mais de $25 \%$ ao ano, para uma produção anual que excedera 300 mil passaportes, em comparação com 210 mil em 2013 (HAITI LIBRE, 2014).

Isso permitiu entender que o não registro no cartório pode ser explicado pela necessidade prática do documento, isto é, sua efetiva utilização no dia a dia. Por um lado, leva a pensar que a documentação não proporciona ao haitiano benefícios significativos em seu próprio país, no entanto passa a ser de interesse quando se trata de deixá-lo. Mais e mais pedidos estão sendo feitos para regularizar os problemas de registro nos arquivos. Em 2017, o país experimentou a maior migração em sua história, cerca de 400 haitianos por dia. Em 2014, havia menos de 1,8 mil haitianos no Chile. Em abril de 2018, eram quase 120 mil, de acordo com os números oficiais. Segundo a polícia 
judiciária chilena, nos seis meses entre $1^{\circ}$ de janeiro e 26 de julho de 2017 , mais de 44,2 mil haitianos entraram em território chileno. Este é um aumento de 75\% em relação ao ano anterior (OIM, 2018).

O governo viu uma oportunidade para preencher as lacunas orçamentárias, elevando o custo dos serviços. O preço dos documentos de identidade aumentou significativamente, especialmente o passaporte e o cartão de identificação nacional. As taxas impostas para emissão de passaporte, no ano fiscal de 2017-2018, foram: 2,5 mil gourdes (cerca de US\$29) para menores de 18 anos e 6 mil gourdes (cerca de US\$ 72) para os adultos, o que representou um aumento de $60 \%$. O cartão de registro é mil gourdes (cerca de US\$ 12) para pessoas físicas empregadas, e 250 gourdes (cerca de US\$ 3) para trabalhadores temporários e candidatos a emprego.

Entretanto nada tem sido feito para mudar a situação e solucionar esses problemas, que impedem o bom funcionamento do sistema. Para um país onde a migração está culturalmente enraizada, e tem sido socialmente necessária, cada obstáculo aumenta consideravelmente a dificuldade para a saída do Haiti, aumentando a probabilidade entre os mais vulneráveis de escolher uma migração perigosa. Para obter os documentos básicos de identidade, o cidadão deve se informar de um processo cujos passos a seguir não são tão simples para a maioria da população. Além disso, a fragilidade do sistema de identificação não consegue alcançar sequer todos aqueles que se inscrevem nos serviços, que dirá todos os habitantes. Também não é possível, para as vítimas de desastres naturais, retirar uma segunda via de seu documento.

A documentação é um instrumento básico de acesso à cidadania nos Estados modernos, condição que deveria estar garantida a também todos os haitianos e haitianas, sem discriminação e sem exclusão, pré-requisito que o Estado haitiano vem falhando, historicamente, em assegurar.

*Artigo recebido em 20 de outubro de 2020, aprovado em 25 de maio de 2021.

\section{REFERÊNCIAS}

BARTHELEMY, Gérard. Le pays en dehors, Essai sur l'univers rural haïtien. Port-au-Prince, Editions Henri Deschamps.1993.

BERTIN, Anne ; DROGUE, Cindy. Haïti : le casse-tête de l'état civil. Pleindroit, v. 3, n. 94, pp. 2730. 2012.

BOURDIEU Pierre. La Distinction. Critique sociale du jugement. Edição « Le sens commun”. 1979.

BRUBAKER, Rogers.Au-delà de L'iidentité". Actes de la recherche en sciences sociales, v. $139,2001$. 
BRUSCHI, Christian. La citoyenneté et la nationalité dans l'histoire, Ecarts d'identité - $\mathrm{N}^{\circ} 75$, dec1995.

CARRARA, Sergio. A sciencia e a doutrina da identificação no Brasil. Religião \& Sociedade, Rio de Janeiro, v. 15, n.1. 1990.

CARVALHO, José Murilo. Cidadania no Brasil: o longo caminho. Rio de Janeiro, Civilização Brasileira, 2016.

CASIMIR, Jean. Haïti et ses élites : l'interminable dialogue de sourds. Port-au-Prince, Édition de l'Université d'Etat d'Haïti, 2006.

CASTOR, Susy. L'occupation américaine d'Haïti. Port-au-Prince, Société haïtienne d'histoire, 1971.

CHALLENGES. Repenser l'état civil pour mieux planifier le développement (dossier).15/o1/2016. Disponível em https://challengesnews.com/repenser-letat-civil-pour-mieuxplanifier-le-developpement/. Acesso em 15 mar. 2021.

CORDEIRO, Rosineide. Vida de agricultoras e histórias de documentos no sertão central de Pernambuco. Estudos Feministas, v. 15, n. 2, p. 453-460, 2007.

CORTEN, André. L'État faible. Haïti et République Dominicaine. Montréal, Les Éditions Mémoire d'encrier, 2011.

DAMATTA,Roberto. A mão invisível do Estado: Notas sobre o significado cultural dos documentos na sociedade brasileira, Anuário Antropólogico, p. 37-64, 2002.

DE LA RIVIÈRE, Claire Jude. Du sceau au passeport. Genèse des pratiques médiévales de l'identification. In: Noirel,Gérard. (éd.) L'identification. Genèse d'un travail d'État, Berlin, Coll. « Socio-histoires »,2007.

DENIS, Vincent. Administrer l'identité . Labyrinthe, n. 5. 2000.

DENIS, Vincent, «Imposteurs et policiers au siècle des Lumières ». Politix, $\mathrm{n}^{\circ}$ 74. pp. 11-3. 2006

DIAL - Diffusion de l'information sur l'Amérique latine. 1990. HAÏTI: Les Aléas de l'état civil des naissances. 26/07/1990, p. 5. Disponível em http://www.alterinfos.org/archives/DIAL1515.pdf. Acesso em 15 mar. 2021.

FOUCAULT, Michel. Em defesa da sociedade, Curso no College de France (1975-1976). São Paulo, Martins Fontes, 2005.

FOUCAULT, Michel. Dits et écrits, tome IV, Paris, Gallimard, 1994.

GARR (Groupe Appui Refugiés Rapatriés). État-civil et exigences françaises: les Haïtien(ne)s pris (es) en tenaille. Groupe d'appui aux rapatriés et aux réfugiés. 2013.

GARR (Groupe Appui Refugiés Rapatriés). Diagnostic sur l'enregistrement Civil et l'identification nationale en Haïti : Les populations à risques, 2007.

HAITI LIBRE. Haïti-Social : Vers une augmentation de la production de passeport, 6 mars 2014 . 
HAITI LIBRE. Haïti - Politique : Échec du PIDIH, un fiasco de 2 millions de dollars, 6 Juillet 2015. Disponível em https://www.haitilibre.com/article-14432-haiti-politique-echec-dupidih-un-fiasco-de-2-millions-de-dollars.html. Acesso em 21 mar. 2021.

HUMAN RIGHTS WATCH, Haiti événements de 2018. 2018. www.hrw.org

LABELLE, Micheline. Idéologie de couleur et classes sociales en Haïti. Montréal : Les Presses de l’Université de Montréal, 1987.

LAENNEC, Hurbon.(dir). La genèse de l'Etat haïtien (1804-1859). Paris, Editions de la Maison des sciences de l'homme, 2009.

LOUIS, Laura. Des millions d'Haitiens n'existent pas au regard de l'état civil. Ayibopost. 12 Fevreiro 2020 ». Acesso em 15 mar.2019.

MACDONALD, Charles. L'Identité. Séminaire interdisciplinaire dirigé par Claude Lévi-Strauss, professeur au Collège de France, 1974-1975.L'Homme.v. 18, n. 3-4. pp. 199-201.1978.

MENARD, Évelyne Trouillot. L'éducation en Haïti: inégalités économiques et sociales et question de genre. La femme dans l'enseignement supérieur. Haïti Perspectives. Vol. 2. No 3, 2013

MINISTERE DE LA JUSTICE. Petit guide à l'usage des officiers d'état civil, Juillet 1984

MONITEUR, La carte d'identification nationale (CIN). 7 Juillet 2005. http://oni.gouv.ht/wpcontent/uploads/2020/05/decret.pdf.

MORAL, Paul. Le paysan haïtien; étude sur la vie rurale en Haïti. Paris, G.P. Maisonneuve\&Larose, 1961.

NOIRIEL, Gérard. L'identification des citoyens.Naissance de l'état civil républicain. Genèses, n. 13, pp. 3-28.1993.

OIM (Organisation Migration Internationale). L'OIM publie un rapport sur les indicateurs de la migration dans le monde 2018. 10/12/18. Disponível em:<https://www.iom.int/fr/news/loim-publie-un-rapport-sur-les-indicateurs-de-la-migrationdans-le-monde-2018>. Acesso em 22 mar. 2021.

ONU. Organisation des Nations Unies. Manuel de statistiques de l'état civil. New York.1985.

PERDOMO CORDERO, Nassef. Análisis crítico de la sentencia TC/o168/13. Memorias : Revista Digital de Historia y Arqueología desde el Caribe Colombiano, Barranquilla, n. 28, pp. 93-136, Jan.-2016. http://www.scielo.org.co/scielo.php?script=sci arttext\&pid=S1794$\underline{88862016000100005 \& \operatorname{lng}=\mathrm{en} \& \mathrm{nrm}=\mathrm{iso}}$. Acesso em 17 mai. 2021.

PÉRICLES, Nathanael. Ethnographie de l'état civil haïtien et les rapports des administrés au système dans le processus d'identification de la population. Port-au-Prince, Sous la direction du professeur Maud Laëthier, En vue de l'obtention du grade de Maitre en Anthropologie, mimeo, 2016.

RELIEFWEB, Le GARR appelle à une concertation des deux Etats de l'île pour mieux orienter le PIDIH et le PNRE. GARR-Haïti. 2015. https://reliefweb.int/report/haiti/le-garr-appelle-uneconcertation-des-deux-etats-de-l-le-pour-mieux-orienter-le-pidih-et. Acesso em 27 set. 2021. 
RICOLDI, Arlene. A pesquisa de campo sobre documentação de mulheres trabalhadoras rurais: limites e possibilidades. In : RICOLDI, Arlene (org.) Mulheres Rurais e documentação : um direito conquistado. São Paulo: Fundação Carlos Chagas, 2017, p. 127-149.

ST SAUVEUR, François. Considérations sur la situation anthropojuridique des paysans non inscrits aux registres d'état civil en Haïti : le cas de chardonnette. Port-au-Prince. Graduação (Mémoire de licence). Faculté d’Ethnologie, 2010. 